INTERNATIONAL JOURNAL OF RESEARCHES IN BIOSCIENCES, AGRICULTURE AND TECHNOLOGY (c) VISHWASHANTI MULTIPURPOSE SOCIETY (Global Peace Multipurpose Socie ty) R. No. MH-659/13 (N) www.vmsindia.org

\title{
PREVALENCE OF VANCOMYCIN RESISTANCE STAPHYLOCOCCUS AUREUS AMONG MRSA ISOLATES FROM DISTRICT HOSPITAL GADCHIROLI (M.S.) INDIA
}

\author{
Y. W. There ${ }^{1}$, V. S. Wadhai ${ }^{2}$, P. Bhandari ${ }^{3}$ \\ 1Taywade College, Koradi, Nagpur (M.S.), India \\ ${ }^{2}$ CHLRM, Sardar Patel Mahavidyalaya, Chandrapur (M.S), India \\ ${ }^{3}$ Se vadal Mahila Mahavidyalaya, Nagpur(M.S.), India \\ yogeshwthere@gmail.com
}

\begin{abstract}
Introduction: Staphylococcus aureus is the frequently isolated from patients with se rious healthcare-associated infections (HAI). Methicillin \& Vancomycin Resistant Staphyloco ccus aureus infections are a tremendous, and growing, burden for healthcare systems and hospitals, and are associated with significant healthcare costs. So there is need to continuous monitoring of development of resistant to avoid fall in pre antibiotic era. The main objectives of this study was to find out the antibiogram patterns of S.aureus, the prevalence of methicillin resistant S.aureus and demonstration of Vancomycin resistance among MRSA strains at the tribal region Gadchiroli (M.S.), India. Method: From Government district hospitals, Gadchiroli the total 234 clinical samples were collected from different source and 114 samples were positive for $S$. aureus. Out of these 78 clinical samples were positive for coagulase test. The pure isolates of coagulase positive S.aureus were screened on Oxacillin re sistant screen agar and tested for antimicrobial susceptibility by using standard methods. Results: Out of 78 clinical specimens samples we re found to be coagulase positive S.aureus. The antibiotics oxacillin, penicillin, erythromycin, gentamycin and tetracyclin had shown maximum resistance on disc diffusion. Amikacin, chloramphenicol and vancomycin antibiotics had showed high sensitivity to all resistant strains of MRSA. The noticeable result in this region was nitrofurantoin had shown around $50 \%$ resistance. Of the isolates 50 is olates were methicillin resistant S.aureus (MRSA). According to Disc Diffusion method the Prevalence rate of MRSA was found $64.10 \%$ and Vancomycin resistant among MRSA isolates was found 16\%. MIC By Etest method had shown MRSA (48.71\%) and VRSA(13.15\%). Conclusion: Our study emphasizes the need for continuous monitoring of the antimicrobial susceptibility pattern of S.aureus isolates including MRSA for the selection of appropriate therapy. Gadchiroli is the backward tribal region of Vidarbha, from the present findings it appears that the spread of MRSA in community is very high and the vancomycin which is the last choice for the treatment MRSA strains also shown re sistant. So there is need of high alert in hospital settings and need of continuous monitoring and surveillance to control resistance.
\end{abstract}

Keywords: MRSA, VRSA, Antibiotics and Oxacillin

\section{Introduction}

Healthcare-associated methicillin-resistant S. aureus (MRSA) is a major cause of nosocomial infections worldwide, with significant attributable morbidity and mortality in addition to pronounced healthcare costs. Many hospitals struggle with increasing amounts of MRSA, which are "multi-resistant" against all betalactam antibiotics. Often, applicable antibiotics for treatment are only glycopeptides like vancomycin and teicoplanin ${ }^{9}$. Methicillinresistance in S.aureus occurs when an isolate carries an altered penicillin binding protein, PBP2a, which is encoded by a $50 \mathrm{~kb}$ piece of $D N A-m e c A$ gene which generates the production of an altered cell wall component (PBP2a) to which penicillins and cephalosporins cannot attach. Methicillin resistant Staphylococcus aureus (MRSA) strains have become endemic in hospitals worldwide. Antibiotic resistant pathogen constitutes an important and growing threat to public health. Healthcare as sociated
Methicillin-resistant Staphylococcus aureus (MRSA) is a major cause of nosocomial infection with significant attribute morbidity and mortality in addition to pronounced healthcare cost1. Many hospital struggles with increasing amount of MRSA which are multi-resistant against all beta-lactum antibiotics. Gadchiroli city is a Tribal region of Maharashtra state, limited reports we re available on development of Methicillin and other antibiotics resistant Staphylococcus aureus form this part of India. The purpose of present study was to evaluate current antimicrobial susceptibility patterns of Staphylococcus aureus and prevalence of vancomycin resistant Staphylococcus aureus among MRSA isolates.

\section{Materials and Methods}

The present study was conducted on the clinical specimens collected from Government district hospitals, Gadchiroli the total 234 clinical samples were collected from diffe rent source and 
114 samples were positive for $S$. aureus. Out of which specimen was found to be coagulase positive Staphylococcus aureus. Of the 78 clinical specimens, 48 specimens were from pus, 18 we re from burn patient and 12 from sputum sample. Standard procedure was followed for isolation and identification of S.aureus and to perform antimicrobial activity ${ }^{7}$.In brief the specimen was collected in sterile container and transport to the laboratory. The specimens were then immediately inoculated nutrie nt broth tube and incubate overnight at $37^{\circ} \mathrm{C}$ for enrichment. Then the loop full of sample transfer to the Blood agar and the Mannitol Salt Agar and were incubated at $37^{\circ} \mathrm{C}$ for $18-24$ hours. The suspected isolated colonies were exposed to Gram's staining and other biochemical test. Staphylococcus aureus organisms were confirmed mainly by positive DNase test and coagulase tests. Confirmed coagulase positive S.aureus isolates were screened for methicillin resistant on Oxacillin resistant screen agar. Methicillin resistant $S$. aureus were further subjected to antimicrobial sensitivity testing by standard disk diffusion method and minimum inhibitory concentration by E-test method as per NCCLS standards2,3,7,10. All the culture media, antibiotics discs and E-test strips were obtained from Hi media laboratory.

\section{Results}

From Government district hospitals, Gadchiroli the total 234 clinical samples were collected from different source and 114 samples we re positive for $S$. aureus. Out of these 78 clinical samples were positive for coagulase test (Table 1) [figure 1]. Out of total, 42 (53.84\%) and 36 (46.16\%) of Staphylococcus aureus isolates were isolated from males and females, respectively. The age wise distribution of total patients with Coagulase positive $S$. aureus infection were as follows; the age group 0-10 years included $19(24.36 \%), \quad 11-20$ years $02(02.56 \%) ; 21-30$ years $03(03.85 \%) ; 31-40$ years $05(06.41 \%) ; 41-50$ years $22(28.21 \%) ; 51$ 60 years $19(24.36 \%) ; 61-70$ years $08(10.26 \%)$; and $71-80$ years $00(0.00 \%)$. In this region 41 50 and 51-60 age groups population were extremely affected with Staphylococcus aureus infection.

\subsection{Overall resistant patterns of $S$. aureus} A total of 78 viable strains of $S$. aureus from Gadchiroli region were tested for antimicrobial susceptibility by disc diffusion. The antibiotic susceptibility test by disc diffusion was done on each isolate by using 12 antibiotics; Oxacillin (OX), Amikacin (AK), Tetracycline (TE), Erythromycin (E), Gentamycin (GN), Methicillin (MET), Chloramphenicol (C), Penicillin (P), Tobramycin (TB), Norfloxacin (NX), Nitrofuranto in (NF) and Vancomycin (V).

The overall resistance pattern of each antibiotic tested was as follows; oxacillin 50 (64.10\%), Amikacin 17 (21.79\%), Tetracycline 42 (53.85\%), Erythromycin 62 (79.49\%), Gentamycin 46 (58.97\%), Me thicillin $50 \quad$ (64.10\%), Chloramphenicol 12 (15.38\%), Penicillin 78 (100.00\%), Tobramycin 59 (75.64\%), Norfloxacin 53 (67.95\%), Nitrofurantoin $44(56.41 \%)$ and Vancomycin 08 (10.26\%) (Table 2) [Figure 2].

3.3 MIC of Methicillin and Vancomycin by Etest method

All methicillin resistant $S$. aureus strains found on Disc Diffusion method and ORSAB were further tested for Minimum Inhibitory Concentration (MIC) by Etest method for methicillin and vancomycin antibiotics. Moreover, the result of susceptible strains has MIC's to oxacillin of $<4 \mathrm{mg} / \mathrm{L}$. Oxacillin Ete st were read after 24 hours and after 48 hours. After that, if the reading is ne gative, the sample was conside red as MSSA strain.

The pattern of antimicrobial susceptibility using MIC's on two antibiotics was as follows; oxacillin was resistant to $38(76.00 \%)$ and $12(24.00 \%)$ sensitive; vancomycin was resistant to 05 $(62.50 \%)$ and se nsitive to 03 (37.50\%) (Table 3). 3.4 Incidence of MRSA and VRSA in Gadchiroli region

The incidence rate of methicillin resistance among 78 coagulase positive $S$. aureus isolates on disc diffusion and MIC was $64.10 \%$ and $48.71 \%$ respectively as shown in Table 4. Antimicrobial susceptibility test by MIC is considered as gold standard; therefore the prevalence rate of MRSA in Gadchiroli region was $48.71 \%$. According to MIC test the incidence rate of VRSA among MRSA isolates was found $13.15 \%$.

Table 1: Coagulase positive $\&$ negative with number of samples of $S$. aureus in Gadchiroli

\begin{tabular}{llll}
\hline Sample & CoPSA & CoNSA & Total \\
\hline Pus & 48 & 14 & 62 \\
Sputum & 12 & 12 & 24 \\
Burned Wound & 18 & 10 & 28 \\
\hline Total & 78 & 36 & 114 \\
\hline
\end{tabular}


Table 2: Over all distribution of antimicrobial susceptibility of $S$. aureus on disc diffusion in Gadchiroli (Total No. 78)

\begin{tabular}{lllll}
\hline \multirow{2}{*}{$\begin{array}{l}\text { Nr. } \\
\text { No. }\end{array}$} & Name of Antibiotic & \multicolumn{2}{l}{ Resistant } & \multicolumn{2}{l}{ Sensitive } \\
\cline { 2 - 5 } & No. & $\%$ & No. & $\%$ \\
\hline 1. Oxacillin (Ox) & 50 & $64.10 \%$ & 28 & $35.90 \%$ \\
2. Amikacin (Ak) & 17 & $21.79 \%$ & 61 & $78.21 \%$ \\
3. Tetracycline (Te) & 42 & $53.85 \%$ & 36 & $46.15 \%$ \\
4. Erythromycin (E) & 62 & $79.49 \%$ & 16 & $20.51 \%$ \\
5. Gentamycin (GN) & 46 & $58.97 \%$ & 32 & $41.03 \%$ \\
6. Methicillin (MET) & 50 & $64.10 \%$ & 28 & $35.90 \%$ \\
7. Chloramphenicol (C) & 12 & $15.38 \%$ & 66 & $84.62 \%$ \\
8. Penicillin (P) & 78 & $100.00 \%$ & 0 & $0.00 \%$ \\
9. Tobramycin (TB) & 59 & $75.64 \%$ & 19 & $24.36 \%$ \\
1( Norfloxacin (NX) & 53 & $67.95 \%$ & 25 & $32.05 \%$ \\
11 Nitrofurantoin (NF) & 44 & $56.41 \%$ & 34 & $43.59 \%$ \\
12 Vancomycin (V) & 8 & $10.26 \%$ & 70 & $89.74 \%$ \\
\hline
\end{tabular}

Table 3: Antimicrobial susceptibility by MIC on methicillin resistant strains of $S$. aureus found on disc diffusion in Gadchiroli

\begin{tabular}{|c|c|c|c|c|c|}
\hline \multirow{4}{*}{$\begin{array}{l}\text { Sr. } \\
\text { No. }\end{array}$} & \multirow{4}{*}{ Name of Antibiotic } & \multicolumn{4}{|c|}{ Antimicrobial Susceptibility test } \\
\hline & & \multicolumn{4}{|c|}{ MIC } \\
\hline & & \multicolumn{2}{|c|}{ Resistant } & \multicolumn{2}{|c|}{ Sensitive } \\
\hline & & No. & $\%$ & No. & $\%$ \\
\hline 1 & $\begin{array}{l}\text { Oxacillin (OX) } \\
\text { (Total-50) }\end{array}$ & 38 & 76.00 & 12 & 24.00 \\
\hline 2 & $\begin{array}{l}\text { Vancomycin (V) } \\
\text { (Tota1-08) }\end{array}$ & 05 & 62.50 & 03 & 37.50 \\
\hline
\end{tabular}

Table 4: Comparison of antimicrobial susceptibility pattern of MRSA strains identified on disc diffu sion with MIC in Gadchiroli

\begin{tabular}{|c|c|c|c|c|c|c|c|c|c|}
\hline \multirow{3}{*}{$\begin{array}{l}\text { Sr. } \\
\text { No }\end{array}$} & \multirow{3}{*}{$\begin{array}{l}\text { Name } \\
\text { Antibiotics }\end{array}$} & \multicolumn{8}{|c|}{ Antimicrobial Susceptibility Test } \\
\hline & & \multicolumn{4}{|c|}{ Disc Diffusion } & \multicolumn{4}{|c|}{ MIC } \\
\hline & & \multicolumn{2}{|c|}{ Resistant } & \multicolumn{2}{|c|}{ Sensitivity } & \multicolumn{2}{|c|}{ Resistant } & \multicolumn{2}{|c|}{ Sensitivity } \\
\hline 1 & $\begin{array}{l}\text { Oxacillin } \\
\text { (Total-78) }\end{array}$ & 50 & $64.10 \%$ & 28 & $34.90 \%$ & 38 & $48.71 \%$ & 40 & $51.29 \%$ \\
\hline 2 & $\begin{array}{l}\text { Vanco mycin } \\
\text { (Total-50) }\end{array}$ & 08 & $16.00 \%$ & 42 & $84.00 \%$ & 05 & $13.15 \%$ & 33 & $86.85 \%$ \\
\hline
\end{tabular}


CoPSA

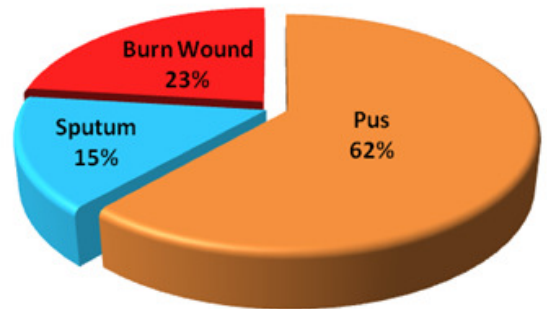

\section{CoNSA}

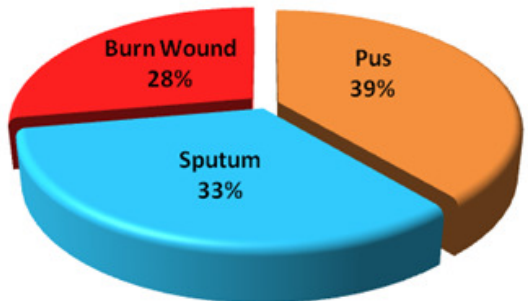

Figure 1: Sample wise Percentage of Coagulase positive S. aureus in Gadchiroli

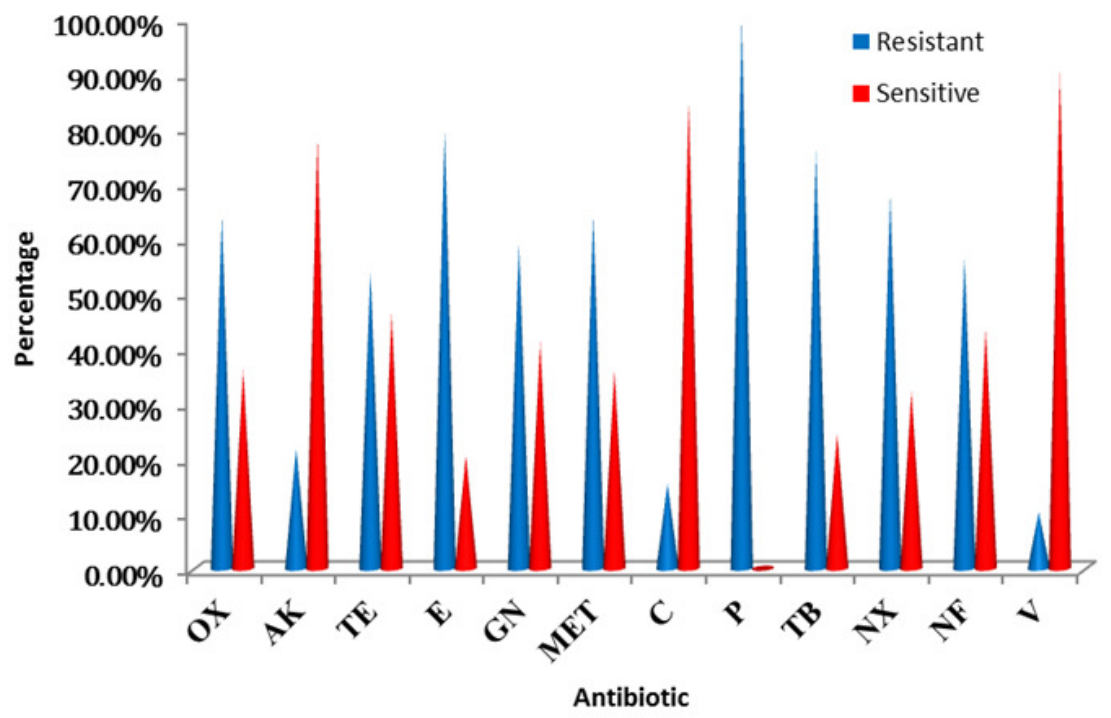

Figure 2 Overall distribution of antimicrobial susceptibility of $S$. aureus on disc diffusion in Gadchiroli

\section{Discussion}

This study was conducted at Gadchiroli district Hospital which is declared as tribal region. Very few reports are available on MRSA from this region. According to antimicrobial susceptibility by MIC Etest method, 38 methicillin resistant isolates were and the prevale nce rate of MRSA is $48.71 \%$. The result were shown that significant rise in antimicrobial resistance in this region as compare to other part of India. In other country the prevale nce rate of MRSA was found different, in India (31$39 \%)$, Pakistan (84\%), Malaysia (40\%), USA $(52 \%)^{14-15}$. The emergence Vancomycin resistance against MRSA strains are great concern. First case of VRSA resistance was reported in 2002(USA) ${ }^{15}$, Then some other countries also reported VRSA resistance. In India Ashdulla et al have reported Vancomycin intermediate S.aureus (VISA) and many reports from north India also recorded the eme rgence of low level and intermediate vancomycin re sistance ${ }^{14-15}$.Venubabu et al reported VRSA strain from Hyderabad in 200916. In our Study out of 38 MRSA strains 05 strains $(13.50 \%)$ had shown vancomycin resistance. So it is quite alarming situation to the community and clinicians. The development of antibiotics resistance may be due to misused and uncontrolled used of drugs without proper diagnosis.

\section{Conclusion}

The present study first time exposed the vancomycin resistance in this part of India. Prevalence rate of MRSA and VRSA was found $48.71 \%$ and $13.15 \%$. These findings are suggesting the need of regularly monitoring the antibiotic resistance patterns of MRSA and implementation of strict rules and regulation on antibiotic usages otherwise; we are supposed to be entering again into pre-antibiotic era. The most effective way to prevent emergence of antibiotic resistance is by continuous surveillance of antibiotic resistance profile, 
reduce misused of antimicrobial drug by proper diagnostic procedure, development of significant new antimicrobial agents and also need of effective education.

\section{References}

[1] Assadullah, S., Kakru, D.K., Thoker, M.A., Bhat, F.A. and Hussain N, Shah, A. (2003): Eme rgence of low level Vancomvcin resistance in MRSA. Indian J Med Microbiol, vol 21:Pp. 196198.

[2] Baird, D. (1996): Staphylococcus: cluster forming gram positive cocci. In: Collee, J.G., Fraser, A.G., Marmion, B.P., Simmons, A., editor. Mackie and McCartney Practical Medical Microbiology. Vol 14: Pp. 245-261

[3] Bauer, A.W., Kirby, W.M.M., She rris, J.C., and Turck, M. ( 1966):Antibiotics susceptibility testing by a standardized single disk method. Am J. ClinPathol, vol 45:Pp.493.

I4l Brooks, G.F., Bute1, J.S. and Morse ,S.A. (2004): The Staphylococci. In : Medical Microbiologv, 23 rd Ed., Meclnick, J., Adelberg (eds): 223-230. McGraw Hill, Ne w York, USA.

[5] Chambers HF. Hadlev WK. and Jawetz E. (1998) Aminoglycosides and spectinomycin. In B. C. Katzung (ed.), Basic and clinical pharmacology. Appleton and Lange, Stamford, Pp. 752-760

[6] Chambers, H. F., W. K. Hadley, and E. Jawetz.(1998) Beta-lactam antibiotics and other inhibitors of cell wall svnthesis. In B. C. Katzung (ed.), Basic and clinical pharmacology. Appleton and Lange, Stampford, Pp.724-742

[7|CLSI (2006): Performance standards for antimicrobial susceptibility testing,fifteenth International supplement, CLSI document $M$ 100-S16, Vol. 26-3; M7-A7, Vol.26-2; M2-A9, Vol. 26-1. Wayne, PA. USA

[8] Hiramatsu, K., Hanaki, ,H, Ino, T., Yabuta, K., Oguri, T., Tenover, F.C. (1997): Methicillin resistant Staphylococcus aureus clinical strain with reduced Vancomycin susceptibility. $J$ AntimicrobChemother, vol 40: Pp.135-136

[9] Hsu,L.Y., Wijaya,L. and Tan, B.H.(2005). Management of healthcare-associated Methicillin-resistant Staphilococcus aureus. Expert. Rev Anti Infect. Ther.Vol 3 :Pp. 893-905.

[10] Isenberg, H. D. (1998): Agar screening test to detect oxacillin (Methicillin) resistant Staphilococcus Spp. In. Essential procedure for Clinical Microbiology.ASM press Washinton DC. Pp.232-234

[11] Khan, F., Shukla, I., and Rivizi, M.(2011): The role of non-beta-lactum antimicrobial and screening for Vancomycin resistance in MRSA. Malaysian J Microbiol, vol 7: Pp.66-70

[12] Naik. D and Teclu A. A (2009): study on antimicrobial susceptibility pattern in clinical isolates of Staphylococcus aureus in Eritrea. Pan African Medical Journal, vol 3:1

[13] Ogeston, A. (1881): Report upon microorganism in surgical diseases. Br. Med.J. vol 1:Pp. 369-37

[14] Saravanan M. Nanda A. and Tesfaye T. (2013) Antibiotic Susceptibilitv Pattern of Methicillin Resistant Staphylococcus aureus from Septicemia Suspected Children in Tertiary Hospital in Hosur, South India American Journal of Microbiological Research,, Vol.1:Pp. 21-24

[15] Tiwary, H. K. and Sen, M. R. (2006): Emergence of Vancomvcin resistant Staphylococcus aureus (VRSA) from tertiary care hospital from Northern part of India. BMC Infectious Dis, vol 6: Pp.156.

[16] Venubabu, T., Channappa, T.S and Subhaschandra, M. G. (2011) Vancomycin resistant among MRSA from intensive care unit of tertiary care hospital in Hydrabad. Indian $J$ Med Res 134:Pp: 704-708 